\title{
Investigating the Impact of Mobility Models on MANET Routing Protocols
}

\author{
Ako Muhammad Abdullah ${ }^{1}$, Emre Ozen ${ }^{2}$, Husnu Bayramoglu ${ }^{3}$ \\ Faculty of Art \& Science, Dept. of Applied Mathematics \& Computer Science ${ }^{1}$ \\ School of Computing and Technology, Dept. of Information Technology $y^{2,3}$ \\ Eastern Mediterranean University (EMU), Famagusta, North Cyprus, Mersin 10 Turkey
}

\begin{abstract}
A mobile ad hoc network (MANET) is a type of multi-hop network under different movement patterns without requiring any fixed infrastructure or centralized control. The mobile nodes in this network moves arbitrarily and topology changes frequently. In MANET routing, protocols play an important role to make reliable communication between nodes. There are several issues affecting the performance of MANET routing protocols. Mobility is one of the most significant factors that have an impact on the routing process. In this paper, FCM, SCM, RWM and HWM mobility models are designed to analyze the performance of AODV, OLSR and GRP protocols, with ten pause time values. These models are based on varying speeds and pause time of MANET participants. Different node parameters such as data drop rate, average end-to-end delay, media access delay, network load, retransmission attempts and throughput are used to make a performance comparison between mobility models. The simulation results showed that in most of the cases OLSR protocol provides better performance than other two routing protocols and it is more suitable for networks that require low delay and retransmission attempts, and high throughput.
\end{abstract}

Keywords-MANET; routing protocols; AODV; OLSR; GRP; node mobility

\section{INTRODUCTION}

Mobile Ad hoc Network (MANET) is a collection of wireless mobile nodes without requiring any pre-existing network infrastructure. The nodes are free to join and leave the network at any time. Each wireless mobile node can communicate with the other nodes and forward data. However, the characteristics of these nodes changes quickly in term of battery power, processing ability, size, and transmission range [1]. In MANET, some nodes can operate as clients, whereas others as servers and few nodes, depending on the network situation, may be flexible to operate as client and server at the same time. Moreover, the topology of these networks changes rapidly due to the independent and random movement of the nodes within the network. Consequently, the arbitrary movement of these nodes changes the entire topology dynamically in an unpredictable manner. In order to transmit information from the source node to the destination node, MANET relays on two methods. If both of the nodes are within the same transmission range, they can exchange information immediately. Otherwise, the intermediate nodes are used to exchange information between the source and destination node.
In recent years, with emerging wireless technology and increasing demand on wireless devices by end users, such as smartphones, Wi-Fi capable laptops, etc., ad hoc networks are becoming more popular. Since MANET has a dynamic nature and there is no need for any infrastructure to deploy on the network, it can be used in many different application areas. Additionally, this type of network is both convenient to use in small networks such as conference rooms and large networks like medical emergency, military communications between the vehicles, soldiers and military data headquarters.

The network connection, the existing infrastructure and electricity are often destroyed or damaged in the case of natural disasters such as flood, earthquake and fire. MANETs can be deployed quickly in order to overcome the problems and better handle the consequences of such disasters [2]. Furthermore, MANETs have been proposed to establish in other areas such as environment monitoring [3] and vehicular communication [4], [5], [6].

Routing protocols in MANETs are the most significant part in order to find the optimal path for transmitting the information from the source node to the destination node. Due to the dynamic topology in MANET, it is difficult to develop an accurate, efficient, effective and reliable routing protocol to establish communication between wireless mobile nodes. These days, there are a number of routing protocols that have been developed for the mobile ad-hoc networks. These routing protocols can be divided into three main categories: Reactive, Proactive and Hybrid routing protocols. In order to evaluate and analyze the performances of routing protocols, several simulations have been done with varying network sizes, data types and parameters. In this study, the impact of mobility on the performance of AODV, OLSR, and GRP MANET routing protocols are investigated in order to identify the performances under different conditions and parameters.

The rest of this paper is organized as follows: Section 2 presents the related works on the performance evaluation of MANET routing protocols. In Section 3, the main features of AODV, OLSR, and GRP routing protocols are explained. Section 4 gives a brief discussion on randomly based mobility models. Section 5 explains the metrics that are used to evaluate the performance of AODV, OLSR, and GRP protocols. Simulation setup is discussed in Section 6. The results of this study are analyzed in Section 7 and Section 8 concludes the paper. 


\section{RELATED WORK}

In the recent years, there are many research papers published on evaluating the performance of MANET routing protocols under different metrics. Most of the papers concentrate on network size variations with traffic load using constant bit rate (CBR) traffic instead of mobility models and pause time of nodes. However, these papers do not observe some of the significant parameters in the network such as data drop rate and retransmission attempts, to analyze the performance of MANET routing protocols. Rangaraj and Anitha [7] evaluated Random Waypoint (RWP), Manhattan Model (MM) and Pursue Mobility Model (PPM) mobility models in order to analyze the performance of AODV and DSDV routing protocols. They used five metrics to evaluate these protocols: delay, throughput, packet delivery ratio, energy, and overhead. According to their simulation results, mobility models have an impact on the performance of AODV and DSDV routing protocols. Their study showed that the PPM model has the ability to provide the best performance with AODV protocols, if performance metrics are considered.

In [8], Kumari et al. compared the performance of AODV, DSDV, and OLSR routing protocols based on different parameters such as packet delivery ratio, routing overhead, packet loss and end-to-end delay under various mobility speed of nodes in the network. Based on the results, OLSR and DSDV generated less end-to-end delay compared to AODV. Also, AODV had less routing overhead than DSDV. On the other hand, the results indicated that when the node speed increases in the network, packet delivery ratio decreases for all routing protocols. However, this study does not consider any results about packet loss in the network.

In [9], Appiah et al. compared the performance of DSR and OLSR protocols based on random waypoint mobility model under different routing metrics such as average traffic received, average throughput, and average delay. The simulation was carried out in an area of $500 \mathrm{~m} \times 500 \mathrm{~m}$. Two scenarios were used by authors but the number of nodes was same in both of the scenarios, 500 nodes. The node speed in the network was 5 to $10 \mathrm{~m} / \mathrm{sec}$. with a $5 \mathrm{sec}$. pause time. According to their results, for all three performance metrics, OLSR protocol performed better than DSR protocol.

Shams et al. [10] evaluated the performance of AODV and DSDV routing protocols based on four mobility models: Fast Car Model, Slow Car Model, Human Running model and Human Walking Model. They used four different pause times: $0,10,100$, and 450 for every scenario. In their simulations, packet delivery fraction, average end-to-end delay and normalized routing overhead performance metrics were used. According to their obtained results, DSDV routing protocol is more appropriate for Human Running and Human Walking Model than Fast Car and Slow Car Models.

\section{ROUTING PROTOCOLS IN MANET}

Nodes in the MANET need a route to exchange information between a source and a destination node. The intermediate nodes participate to succeed the communication between the nodes when the source node and destination node are not within the same range. Routing protocols play an important role to find the best route for forwarding data to its destination. Different procedures and metrics are used by various routing protocols to determine the optimal path for forwarding the packets between the nodes. Several ways are used to classify MANET routing protocols, but most of these are based on network structure and routing strategy [11]. The wireless node must have the capability to establish and maintain multi-hop routes and guarantee that data is exchanging between nodes. Designing a routing protocol is one of the most significant features of the communication process. In this section, we discuss three MANET routing protocols and some issues that are related to routing protocols in details.

\section{A. Ad-hoc on-Demand Distance Vector (AODV) Protocol}

One of the most commonly used reactive MANET routing protocol is Ad-hoc On-Demand Distance Vector (AODV) Protocol. This protocol is suitable for multicast and unicast routing between participated mobile nodes in the network. AODV has the capability to maintain only the routes that are actively used in a communication [12]. AODV has a crucial role to reduce the number of needed broadcasts messages through the network. To find and maintain the routes, AODV uses four different messages such as Route Request message (RREQ), Route Reply Message (RREP), Route Error Message (RERR), and HELLO Message. When a source node wants to send a packet to a destination node but it has no routing information to reach the destination or if a previously valid route is expired, the source node must discover a path for transferring the packet. To carry out this process, it broadcasts a message called Route Request message (RREQ) to all its neighbors.

The RREQ is one of the four messages that are used by the source node to find the routes. This message continuously propagates across the network until it accesses the destination node. Each RREQ consists of the fields such as Source Address, Request ID, Source Sequence No, Destination Address, and Destination Sequence No, Hop Count [12]. If any of the neighbor node have a route to reach the destination node, it informs the source node by sending a unicast Route Reply (RREP) message. Otherwise, it rebroadcasts the RREQ message to the neighboring nodes. When a node receives RREQ message from a neighbor, it records the address of this neighbor. This address is used by the nodes when they find the destination node. This mechanism is very useful to reduce the number of broadcast messages by nodes in the network. The RREP consists of the fields such as Source Address, Destination Address, Destination Sequence No, Hop Count, and Life Time [13].

During the communication between nodes, some nodes might leave the network or a link may fail at any time since each node in MANET is free to move independently. In this case, nodes use another message called Route Error (RERR) to inform the source node that the link breakage occurred and cannot reach the destination node. After the RERR message is received by the source, if the source node still desires the path, it can re-initiate path discovery [14]. AODV routing protocol uses local broadcast message during the route discovery process called HELLO message. This message helps each node to find its neighbors. Furthermore, this message is 
important to inform the neighbor nodes that the route is still alive for transmitting data [15].

\section{B. Optimized Link State Routing Protocol (OLSR)}

Optimized Link State Routing (OLSR) is a proactive link state routing protocol. It is also known as table-driven protocol because it has the ability to store and update its routing table temporarily. Due to its proactive nature, when a node wants to send a packet to a destination node, the routes are continuously available. Therefore, the protocol considers the minimum delay during a packet transmission over the network. OLSR is an appropriate protocol for large and dense mobile networks since this protocol uses Multipoint Relays (MPR) node technique. This technique plays a significant role to discover the shortest route to the destination node. It is also able to reduce the number of identical retransmission messages in the network compared to other flooding techniques that are used by other MANET routing protocols. Each node in the network has the capability to select a set of its neighbor nodes as an MPR. Furthermore, the MPR selectors set are used by each node to count nodes that have chosen it as an MPR node [12].

OLSR allows nodes to declare their own willingness to operate as MPRs. For this purpose, the protocol uses 8 levels of willingness to define which nodes must be operated as MPRs. The lowest level is called WILL_NEVER (0). The node at this level cannot be selected as an MPR. The highest level is called WILL_ALWAYS (7), which shows that this node can always be selected and operated as an MPR. Willingness is a part of HELLO packet. MPR selection is based on one-hop node that provides the best path to reach the two-hop neighbors [16]. This technique can divide all nodes in the network into different sets. In this case, MPR limits the set of nodes to retransmit packets from all nodes to a subset of nodes in the network. The topology of the network determines the size of this subset of nodes [17]. In OLSR, link state information is created and forwarded only by MPR nodes during the flooding process across the network [18]. In addition, OLSR uses two main types of control messages such as HELLO and Topology Control (TC) messages to find the route and maintain the network topology information. To do that, these messages periodically broadcast throughout the networks.

\section{Geographic Routing Protocol (GRP)}

Geographic routing protocol has the ability to deal with different size of networks since there is no need to maintain the routing table up-to-date. The main idea behind using GRP is that geographic position information is used to forward packets from the source node to the destination node. Consequently, in dynamic topologies, it can provide better performance, especially in large density mobile nodes. In other words, the source node instead of using network address relies on geographic location information to reach the destination node. It exchanges information between the nodes in the network without having the knowledge about prior route discovery or network topology [19].

Moreover, GRP uses two main important mechanisms for forwarding packets in the network: Greedy Forwarding and Face Routing. Greedy Forwarding technique uses local information to transport the packet closer to the destination in each step. The node that has the minimum distance to reach the destination in each step is the most appropriate neighbor node. In Greedy Forwarding, the key difficulty is to choose the correct neighbor node to send the packet. To carry out this step, different routing strategies are used by Greedy Forwarding such as Most Forwarded within R (MFR), Nearest with Forwarded Progress (NFP) and Compass Routing. Based on these strategies a node can decide which neighbor node should be selected for forwarding the packets [20]. When Greedy Forwarding cannot find any neighbor node near to the destination, it can lead to a dead end. Then GRP uses Face Routing approach to recover from that situation and discover a route to another node, where Greedy Forwarding can be started again. Face Routing strategy has a significant role to guarantee that the packet can be reached to the destination node [21].

\section{RANDOM BASED MOBILITY MODELS}

In the considered mobility models, the mobile nodes are free to move from one location to another without limitations. These models play a significant role to evaluate the performance of routing protocols in MANET since they have the ability to deal with randomly selected velocity and acceleration during simulation time for each routing protocol. In recent years, with developing mobile ad hoc network routing protocols, some mobility models have been proposed to evaluate the performance of these routing protocols. The Random Waypoint model is the first model that was proposed by Johnson and Maltz [22]. This model is one of the common models that have been using to evaluate the performance of MANET routing protocols because it is easy to use and widely exist in most of the network simulators.

The procedures of using Random Waypoint is that when the simulation starts to transmit packets from the source node to the destination node, every mobile node chooses one position in the simulation field as the destination point. Then, the nodes move to reach the desired destination with a constant velocity. The speed is selected randomly within the range of $[0, V \max ]$, where $V \max$ denotes the maximum velocity for each mobile node. The direction and velocity of the mobile nodes are selected independent from each other. When the mobile node reaches the destination, it can be stopped for a short time based on the time that is assigned as the pause time, $T$ pause. In the simulation field, the mobile node selects another random destination after the pause time and travels towards it. This process continues until the end of the simulation time [23]. In some case, Tpause $=0$ which means the node continuously moves.

\section{Performance Evaluation Metrics}

Many quantitative metrics can be used to evaluate the performance of MANET routing protocols. In this study, the considered performance metrics are data drop rate, average end-to-end delay, media access delay, network load, retransmission attempts and throughput.

\section{A. Data Drop Rate}

Data Drop rate occurs when the source node wants to transmit data to the destination node but some of the data gets 
lost during the transmission by network congestion or buffer overflow [24].

\section{B. Average End-to- End Delay}

The average end-to-end delay is defined as the average time that an entire packet needs to travel from the sender to the receiver across a network. The end-to-end delay can be calculated as follows:

$\mathrm{EED}=\mathrm{PT}+\mathrm{TT}+\mathrm{QT}+\mathrm{PD}$

Where EED is end-to-end delay, PT is propagation time, TT represents transmission time, QT is queuing time and PD represents processing delay [25].

\section{Media Access Delay}

Media Access Delay is measured as the time from when the data reaches the Media Access Layer (MAC) until it is successfully transmitted out on the wireless medium. This metric is useful since many real-time applications cannot wait for long delays, since, after a specific time, the data becomes useless. For that reason, it is significant to provide a minimum delay for real-time streams.

\section{Network Load}

Network load represents the average amount of data traffic being carried by the network. High network load results in increased number of collisions in the networks and this is one of the factors that degrade the performance of MANET routing protocols

\section{E. Retransmission Attempts}

Retransmission Attempt can be defined as the total number of retransmission attempts done in a network until a packet is successfully transmitted or discarded for some reasons.

\section{F. Throughput}

Throughput is another important metric that is used to evaluate the performance of routing protocols. It is defined as the average rate of data that successfully received by the destination node in the network. Different measurements can be used to measure the throughput such as bits per second (bps), byte per second (Bps) and sometimes data packets per second ( $\mathrm{p} / \mathrm{sec}$ ). In MANET, the throughput can be affected by some factors such as mobility of nodes, traffic load, limited bandwidth, and power constraint [25]. The throughput can be calculated as follows:

Throughput $(\mathrm{bps})=\frac{\text { Number of Delivered Packets } * \text { Packet Size } * 8}{\text { Total Duration of Simulation }}$

\section{SIMULATION SETUP}

The study is carried out via using OPNET (Optimized Network Engineering Tool) Modeler version 14.5. OPNET is one of the most common commercial simulator tools for the research studies that can run on the Microsoft Windows platform. OPNET has the ability to deal with different types of network models. This ability makes the simulator one of the best environments for coordinating and comparing the performances of routing protocols accurately.

Three MANET routing protocols AODV, OLSR and GRP are compared. Performance of routing protocols based on the impact of different mobility models with varying pause time of mobile nodes in the network examined. In simulation scenarios, 75 wireless nodes with a fixed wireless server to support Files Transport Protocol used. The wireless nodes having various speeds were distributed randomly within the network area $1500 \mathrm{~m} \times 1500 \mathrm{~m}$. Total simulation time in all simulation models is 900 seconds as shown in Table 1. In addition, different network entities such as application configuration, mobility configuration, and profile configuration are used in the design of our simulation models. To carry out this study, four different node speeds FCM $(30 \mathrm{~m} / \mathrm{s}), \operatorname{SCM}(10 \mathrm{~m} / \mathrm{s}), \mathrm{RWM}(4 \mathrm{~m} / \mathrm{s})$, and HWM $(2 \mathrm{~m} / \mathrm{s})$ are used.

\section{A. Fast Car Model (FCM)}

In FCM, we assume that the nodes can move like a car at speed $30 \mathrm{~m} / \mathrm{s}$ or $108 \mathrm{~km} / \mathrm{h}$. These mobile nodes move from one station to another station. Furthermore, in this model pause time interval must be considered because the mobile nodes should be stopped for a moment at different breakpoints. As an example, if an ambulance is moving at $105 \mathrm{~km} / \mathrm{h}$, it should stop at different breakpoints.

\section{B. Slow Car Model (SCM)}

SCM is another model that was designed to analyze the performance of AODV, OLSR, and GRP MANET routing protocols. In this model, the car may move at a slow speed compared to the previous model but on a busy street. Therefore, speed is reduced to $10 \mathrm{~m} / \mathrm{s}$ or $36 \mathrm{~km} / \mathrm{h}$.

\section{Race Walking Model (RWM)}

In this model, mobile nodes are considered as human due to the fact that most of the time MANET participants are carried by a human. There is a speed difference between a human walking and a human running. For instance, in battlefield soldiers can walk or run where the average speed is $4 \mathrm{~m} / \mathrm{s}$ or $14.4 \mathrm{~km} / \mathrm{h}$. Moreover, this model can also be used for rescue operations and for some sports.

TABLE I. PARAMETERS OF SIMULATION

\begin{tabular}{|l|l|}
\hline Environment Size & $1500 \mathrm{~m} \times 1500 \mathrm{~m}$ \\
\hline Number of nodes & 75 \\
\hline Protocols & AODV, OLSR, GRP \\
\hline Speed & $\begin{array}{l}\text { FCM }(30 \mathrm{~m} / \mathrm{s}), \text { SCM }(10 \mathrm{~m} / \mathrm{s}), \text { RWM } \\
(4 \mathrm{~m} / \mathrm{s}), \mathrm{HWM}(2 \mathrm{~m} / \mathrm{s})\end{array}$ \\
\hline Performance Metrics & $\begin{array}{l}\text { Data Drop rate, End -to- End Delay, } \\
\text { Media Access Delay, Network Load, } \\
\text { Retransmission Attempts, } \\
\text { Throughput }\end{array}$ \\
\hline Pause Time & $10,20,30,40,50,60,70,80,90,100$ \\
\hline Mobility model & Random Waypoint \\
\hline Application Traffic & FTP Traffic \\
\hline File Size & 20 Frames \\
\hline Data Rate & 11 Mbps \\
\hline Simulation Time & $900 \mathrm{sec}$ \\
\hline Simulator & OPNET 14.5 \\
\hline
\end{tabular}




\section{Human Walking Model (HWM)}

This is similar to the RWM model, but it has different considerations. For instance, people typically walk in festival, campus, or at a shopping mall. HWM model speed is $2 \mathrm{~m} / \mathrm{s}$ or $7.2 \mathrm{~km} / \mathrm{h}$.

\section{RESULTS AND ANALYSIS}

In this section, the results of experiments conducted are presented and discussed aiming to investigate the performance of AODV, OLSR, and GRP MANET routing protocols under the four models FCM, SCM, RWM, and HWM. Data drop rates, end-to-end delay, media access delay, network load, retransmission attempts, and throughput are the metrics used to evaluate the performance of these routing protocols.

\section{A. Data Drop Rate}

Fig. 1(a), (b), (c) and (d) shows the data drop rates of AODV, OLSR, and GRP protocols under various speeds with different pause times. The plots show the data dropped from OLSR is greater than AODV and GRP in FCM, RWM, RWM, and HWM models. However, we can see a very large difference between AODV and the other two routing protocols in all models. AODV shows the best performance among the protocols investigated.

In FCM model data drop rate for AODV is very high when compared to the other models and is equal to 271.6803 bits/sec, while $76.358 \mathrm{bits} / \mathrm{sec}$ in SCM, $71.932 \mathrm{bits} / \mathrm{sec}$ in RWM, and 63.63183 bits/sec in HWM. We can observe that the data drop rate for AODV is very high at speed $30 \mathrm{~m} / \mathrm{s}$ but in other models, AODV protocol gives better performance due to the reduction in speed and pause time have a negligible effect on the performance of AODV. In addition, GRP protocol have quite a high packet drop rate compared to AODV in all models and is equal to $1454.679 \mathrm{bits} / \mathrm{sec}$ in FCM, 1266.727 bits/sec in SCM, 1146.504 bits/sec in RWM, and 1179.5 bits/sec in HWM. In general, it can be observed in Fig. 1(a), (b), (c), and (d) that data drop rate decreases as the speed of nodes decreases. In case of OLSR protocol, data drop rate is the highest for all models and when the mobility increases the data drop rate increases also but it can be seen from the results that the data drop rate remains same for different pause times.

\section{B. Average End -to- End Delay}

Fig. 2(a), (b), (c), and (d) present the average end-to-end delay of AODV, OLSR, and GRP protocols with varying mobility and pause times. It can be seen that due to its proactive nature, MPR selectors, sets and relay messages, OLSR protocol has the lowest delay when compared to the other protocols. MPR selector sets play an important role to reduce the delay in the network. Furthermore, each node can predefine and maintain routes in its routing table to all destinations. The average peak value of OLSR in FCM model is $0.000703 \mathrm{sec}$ and that value decreases when the speed of nodes decreases. OLSR has the minimum delay in the HWM model that is $0.000368 \mathrm{sec}$. Furthermore, RWM and HWM model at speeds i.e. $4 \mathrm{~m} / \mathrm{s}$ and $2 \mathrm{~m} / \mathrm{s}$ can provide a lower delay compared to FCM and SCM models. However, The RWM model for the OLSR protocol at pause time 90 gives a slightly better performance due to the decrease in node speed. In OLSR when node speeds reduced the probability of validity of the routes kept in routing tables rises.

On the other hand, the GRP protocol has lower delay when compared to AODV protocol that is $0.001525 \mathrm{sec}$ in FCM model. The reason for that is the GRP protocols' ability to set up the connection between nodes in the network without considering the real and non-real time traffic. Thus, GRP does not need to maintain explicit routes and instead of using network addresses, it relies on geographic position information for forwarding data from the source node to the destination node in the network. Furthermore, the FCM model for the GRP protocol at pause time 100 provides the lowest delay that is $0.00138 \mathrm{sec}$. In all cases, the value of delay decreases gradually with the reduction of the node speeds. From the figures, we can observe that AODV has the highest delay when compared to the other protocols. AODV is an ondemand protocol, which constructs the connection when necessary that is the source of delay. The average delay of AODV in the FCM model is $0.006484 \mathrm{sec}$ and this value decreases gradually in other models. In the SCM model, the peak value is $0.005429 \mathrm{sec}$. However, in the HWM model Fig. 2(d) it can be seen that average end-to-end delay for AODV is the lowest, hitting to $0.003799 \mathrm{sec}$. In all models, for the all protocols investigated pause time has negligible effect on the performance.

\section{Media Access Delay}

Four models are created to evaluate the media access delay of AODV, OLSR, and GRP protocols. In the first model when the speed is $30 \mathrm{~m} / \mathrm{s}$ as shown in Fig. 3(a) the average media access delay of AODV is greater than average media access delay of the OLSR and the GRP protocols. The average delay value of the AODV protocol is $0.012776 \mathrm{sec}$. This value gradually decreases when the speed decreases and pause time increases. The media access delay value is lower in the RWM and HWM models when compared to FCM and SCM models. However, it is clear in Fig. 3(b) that AODV gives an almost identical performance between the pause times $20 \mathrm{sec}$. and 90 sec. In addition, the media access delay for RWM and HWM models are $0.1244 \mathrm{sec}$ and $0.1232 \mathrm{sec}$ respectively and in the SCM model the media access delay is $0.1531 \mathrm{sec}$.

Moreover, GRP protocol in all cases can provide the lowest media access delay and performs better when compared to AODV and OLSR protocols. GRP protocol also has lower media access delays in RWM and HWM models because there are more link breakages at higher speeds in FCM and SCM. The average delay value for GRP in FCM, SCM, RWM, and HWM are $0.003853 \mathrm{sec}, 0.003694 \mathrm{sec}$, $0.00367 \mathrm{sec}$, and $0.003328 \mathrm{sec}$ respectively. On the other hand, the OLSR protocol performs better than AODV in all cases. However, the pause times does not affect the performance of the OLSR protocol as demonstrated in Fig. 3(a), (b), (c), and (d). The average rate of media access delay for OLSR protocol is $0.004156 \mathrm{sec}$ in the FCM model and $0.00364 \mathrm{sec}$ in HWM mode. 


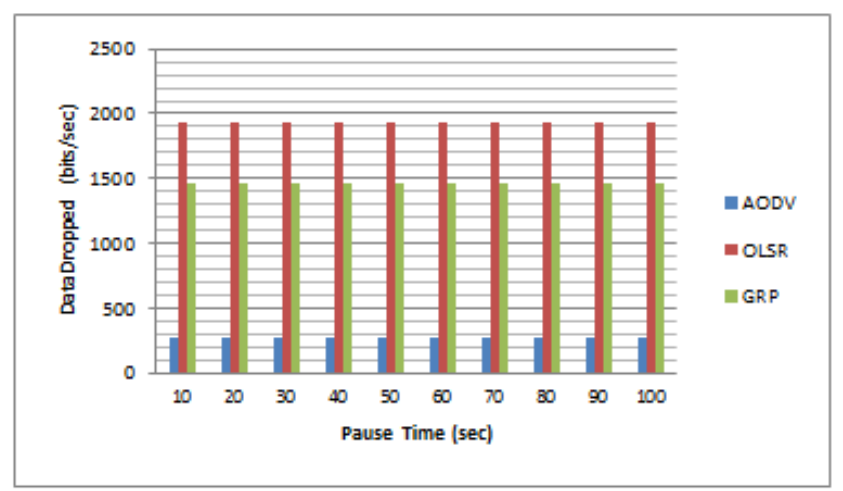

a. $\mathrm{FCM}(30 \mathrm{~m} / \mathrm{s})$

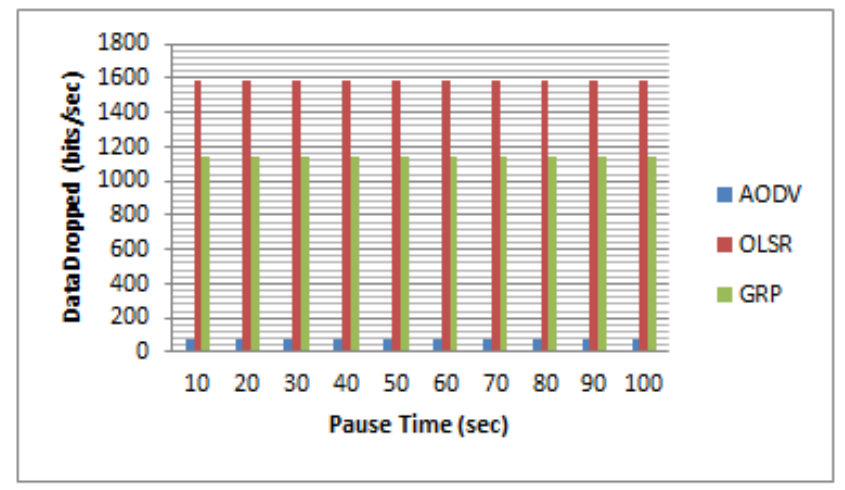

c. $\mathrm{RWM}(\mathbf{4 m} / \mathrm{s})$

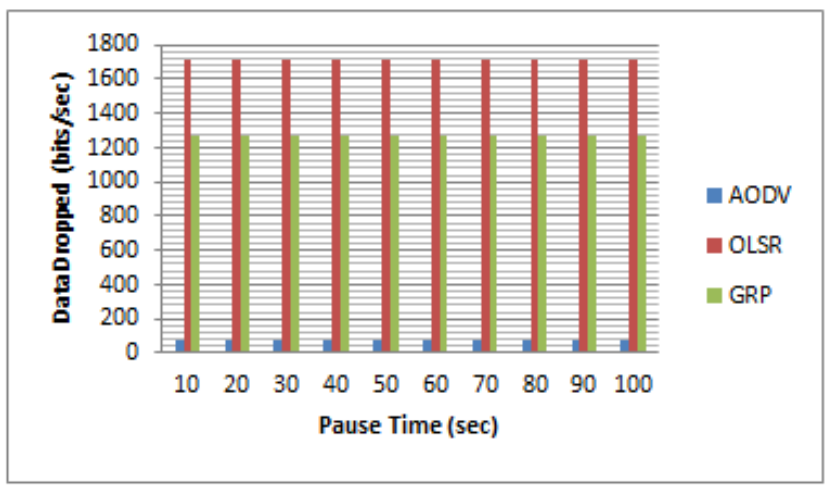

b. $\operatorname{SCM}(10 \mathrm{~m} / \mathrm{s})$

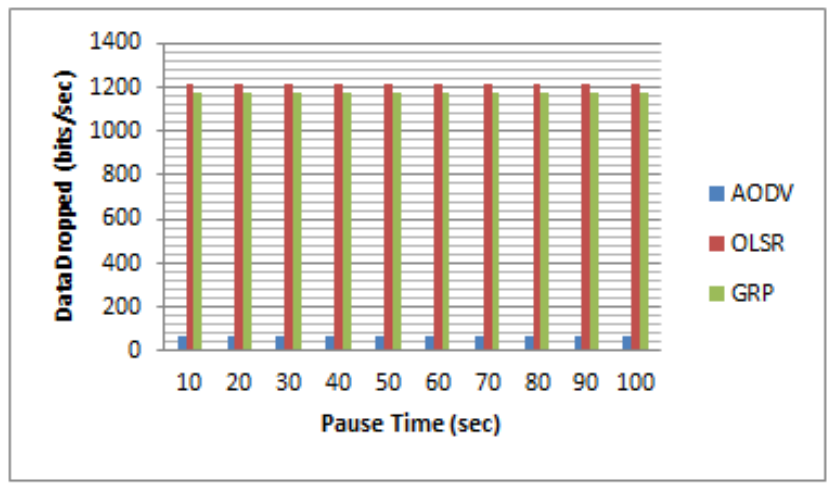

d. HWM (2 m/s)

Fig. 1. Data Drop Rate.

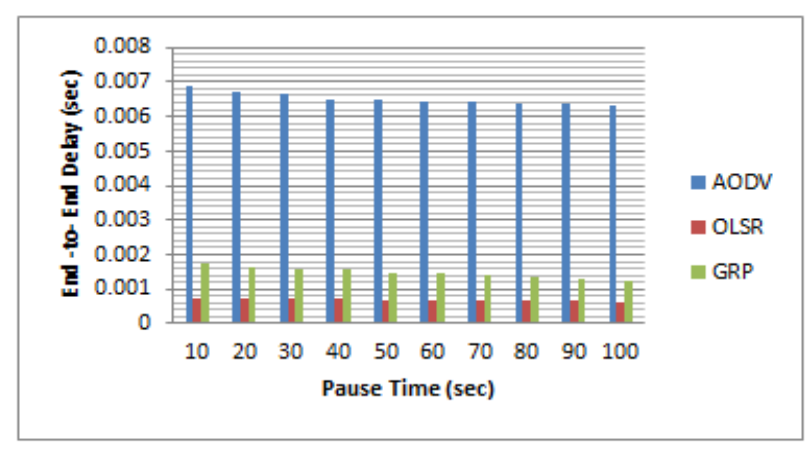

a.FCM $(30 \mathrm{~m} / \mathrm{s})$

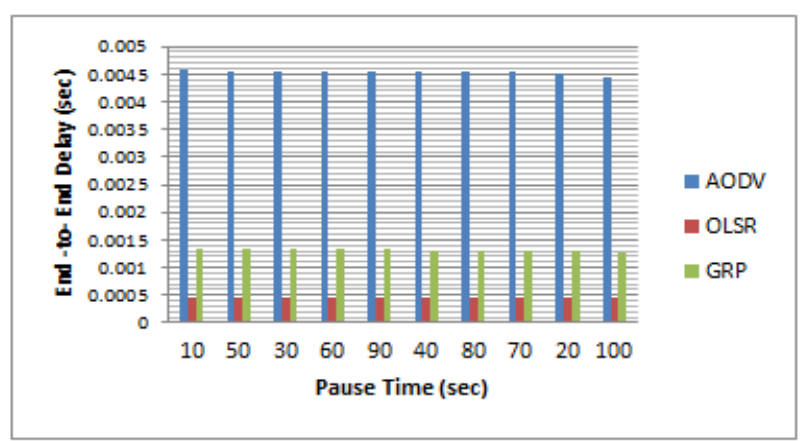

c. $R W M(4 \mathrm{~m} / \mathrm{s})$

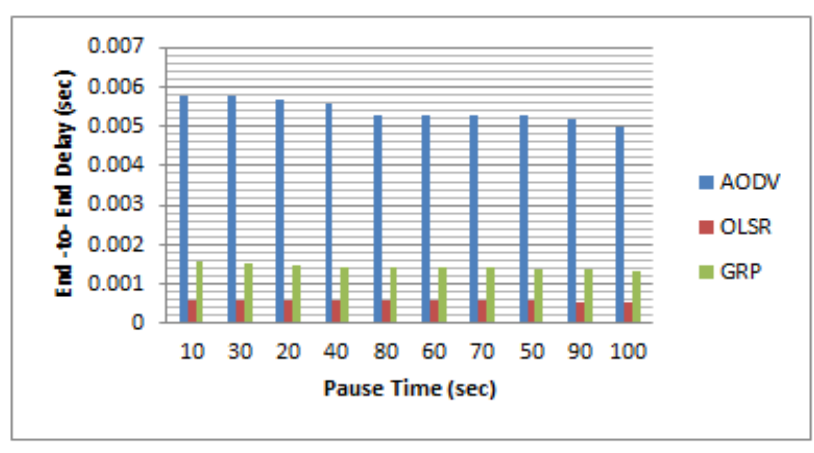

b. $\mathrm{SCM}(10 \mathrm{~m} / \mathrm{s})$

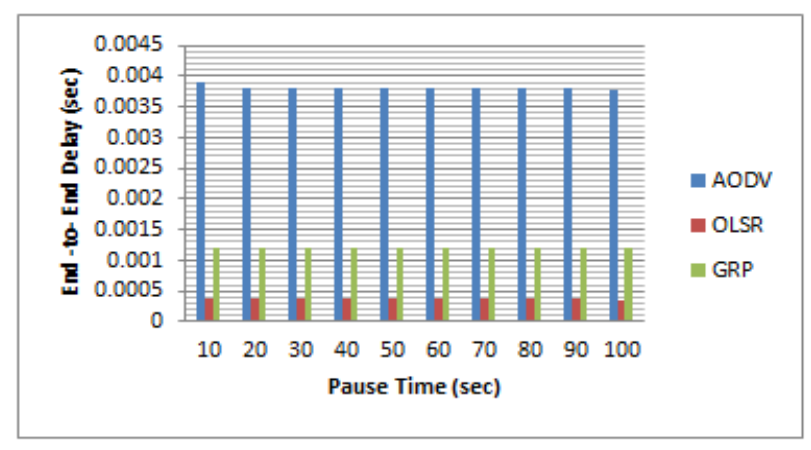

d. HWM $(2 \mathrm{~m} / \mathrm{s})$

Fig. 2. Average End-to-End Delay. 


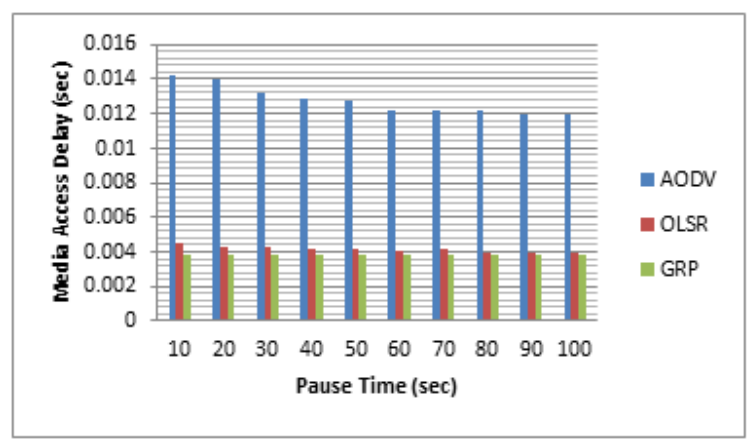

a.FCM $(30 \mathrm{~m} / \mathrm{s})$

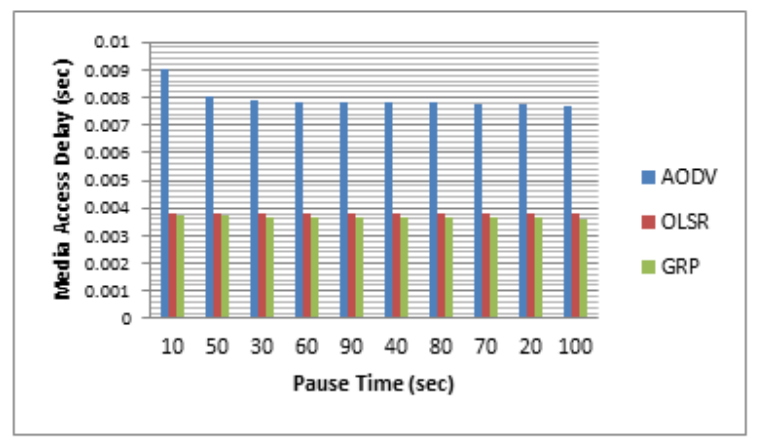

c. RWM ( $4 \mathrm{~m} / \mathrm{s})$

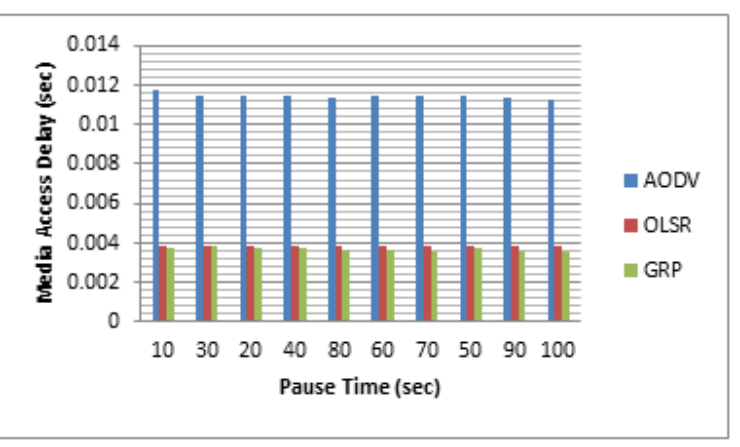

b. $\operatorname{SCM}(10 \mathrm{~m} / \mathrm{s})$

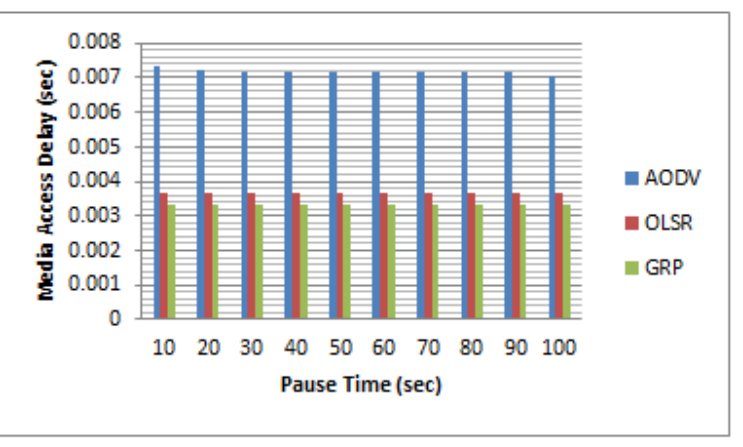

d. $\operatorname{HWM}(2 \mathrm{~m} / \mathrm{s})$

Fig. 3. Media Access Delay.

\section{Network Load}

Fig. 4(a), (b), (c), and (d) represent the network load for AODV, OLSR, and GRP routing protocols. According to the simulation results, OLSR always has the highest network load for all cases when compared to the other two routing protocols. Mobility of nodes in network changes the link state of nodes in OLSR protocol and as a result MPR nodes are changing. Thus, the nodes in the network must periodically broadcast hello and TC messages to maintain and find neighborhood nodes. Furthermore, OLSR is a link state routing protocol that uses a table-driven mechanism which produces more communication overhead and takes more time; as a result the total load in the network increases.

On the other hand, it can be observed from Table 2 and Fig. 4(a) the average network load of the OLSR protocol in the FCM model is $120102.4 \mathrm{bits} / \mathrm{sec}$. However, the values of network loads in other models are gradually decreases and reaches to $114767.6 \mathrm{bits} / \mathrm{sec}$ in the SCM model. On the graph of OLSR network load, the network load peak value is starting from almost $111824.6 \mathrm{bits} / \mathrm{sec}$ for pause time 10 and reaches to almost $111746.3 \mathrm{bits} / \mathrm{sec}$ for pause time 100 in RWM model. Similarly, the load on the network in the HWM model is also showing a different behavior than the RWM model. The peak value of the network load is $110198.5 \mathrm{bits} / \mathrm{sec}$ for the HWM model. AODV in the HWM model has slightly higher network load that is 21968.23 bits/sec when compared to GRP protocols' $17970.58 \mathrm{bits} / \mathrm{sec}$. The average network load in the FCM model for AODV protocol is $29826.48 \mathrm{bits} / \mathrm{sec}$ and gradually decreases in the other three models. In the SCM model average network load is $24442.48 \mathrm{bits} / \mathrm{sec}$. and in the
RWM model the average network load is also decreases and reaches down to $24106.29 \mathrm{bits} / \mathrm{sec}$. But in RWM model for GRP protocol it is 50895.41 bits/sec. for all cases except HWM model GRP protocol has higher network load when compared to AODV protocols' network load as shown in Fig. 4(a), (b), and (c).

\section{E. Retransmission Attempts}

Retransmission Attempts of AODV, OLSR, and GRP protocols are presented in Fig. 5(a), (b), (c), and (d). According to the obtained results GRP protocol has more retransmission packets compared to OLSR and AODV protocols for all cases. It is also observed that increasing the mobility speed increases the retransmission packets as shown in Table 2. The average peak value of GRP protocol in the FCM model is 0.3715 packets/sec. However, decrease in the mobility speed or increase in the pause time, decreases the retransmission attempts for GRP protocol. In SCM model the peak value becomes 0.2535 packets/sec. This value gradually decreases in the remaining models. It can be seen from the table that the retransmission attempts in RWM and HWM models are 0.2384 packets $/ \mathrm{sec}$ and 0.2101 packets $/ \mathrm{sec}$ respectively. When a link broken in the network, the nodes attempt to maintain the connection through other nodes and try to retransmit the packets that are lost during the communication. As a result, the link breakage is the main reason for the increase in the number of retransmission packets on the network.

Furthermore, from the graphs, it is clear that OLSR protocol performs better than AODV and GRP protocols where the reason is being a proactive protocol. The average 
peak value of OLSR protocol in FCM model is 0.0642 packets/sec. This value decreases slightly in HWM model and is equal to 0.0582 packets/sec. In addition, the AODV protocol can provide better performance when compared to GRP protocol. The average rate of retransmission attempts reaches to 0.2421 packets/sec in FCM model. Decreasing the mobility speed causes the decrease in retransmission attempts and it becomes 0.1531 packets $/ \mathrm{sec}$ in SCM model, 0.1244packets/sec in RWM, and 0.1232 packets/sec in HWM model. However, increase in pause-time will affect slightly the AODV protocol, because it is an on-demand protocol and that means connections will be constructed when necessary.

\section{F. Throughput}

Fig. 6(a), (b), (c), and (d) show the throughput for AODV, OLSR, and GRP protocols. In this simulation, the number of nodes is kept constant as 75 and the mobility speed and pause time of the nodes is varied based on models that have been created. According to the results obtained, OLSR performs better than AODV and GRP protocol due to being proactive in nature. However, we can observe that when mobility speed and pause times are increased; OLSR does not have significant decrease in throughput as shown in Table 2 . The average rate of throughput for OLSR protocol in FCM is 8034218 bits/sec.

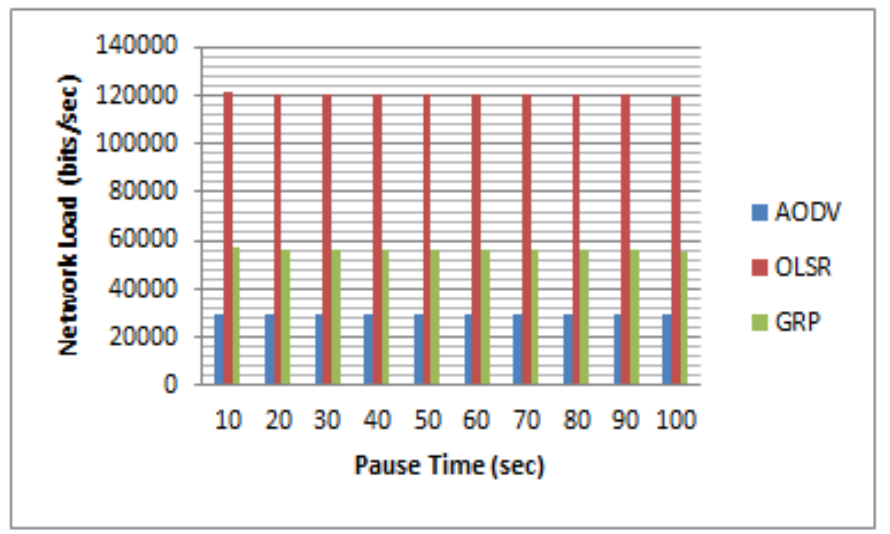

$\operatorname{a.FCM}(30 \mathrm{~m} / \mathrm{s})$

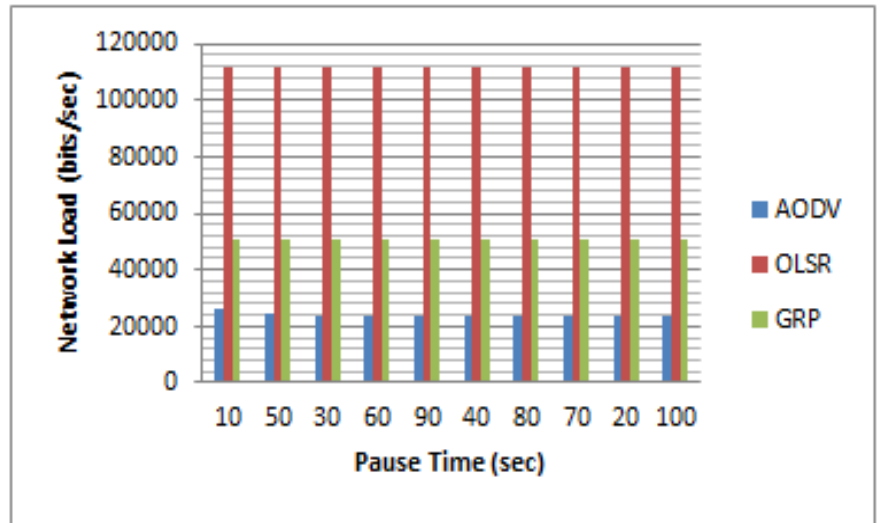

$\operatorname{c.RWM}(4 \mathrm{~m} / \mathrm{s})$
This rate gradually increases when the mobility speed decreases. The average rate of throughput in HWM is $9810472 \mathrm{bits} / \mathrm{sec}$. In addition, we can also observe that the throughput rate of GRP in FCM, SCM, RWM, and HWM have slightly better results than the throughput rate of AODV. The reason is that, the GRP protocol collects information at a source node quickly with the lowest number of control overheads. The source node has the ability to discover the best route based on the gathered position information and then transfers the data continuously as far as the current route is available.

In FCM, GRP throughput rate reaches up to 1238861 $\mathrm{bits} / \mathrm{sec}$, in SCM this value is $1279313 \mathrm{bits} / \mathrm{sec}$, in RWM it is $1288852 \mathrm{bits} / \mathrm{sec}$, and $1312141 \mathrm{bits} / \mathrm{sec}$ is the value for HWM.

The peak value of AODV throughput is $430287.3 \mathrm{bits} / \mathrm{sec}$ in FCM and the average rate of throughput gradually increases when the reduction in speed increases. AODV throughput is equal to 505787.3bits/sec in the SCM model. In Fig. 6(c) and (d) it can be observed that throughput for RWM and HWM models are better than the other two models (FCM and SCM) seen in Fig. 6(a) and (b). However, varying pause time of nodes has a slight effect on the throughput. As it can be seen from Fig. 6, AODV protocol has lower throughput than the other two protocols.

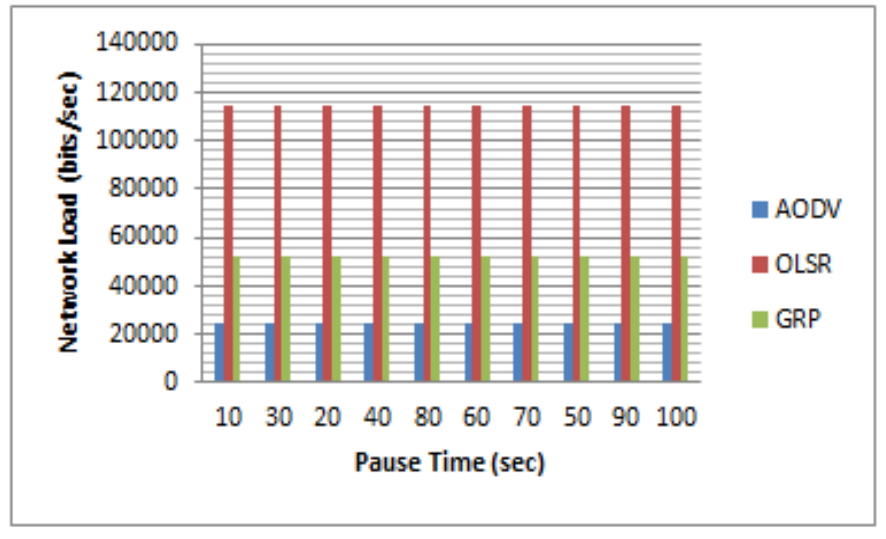

b. $\operatorname{SCM}(10 \mathrm{~m} / \mathrm{s})$

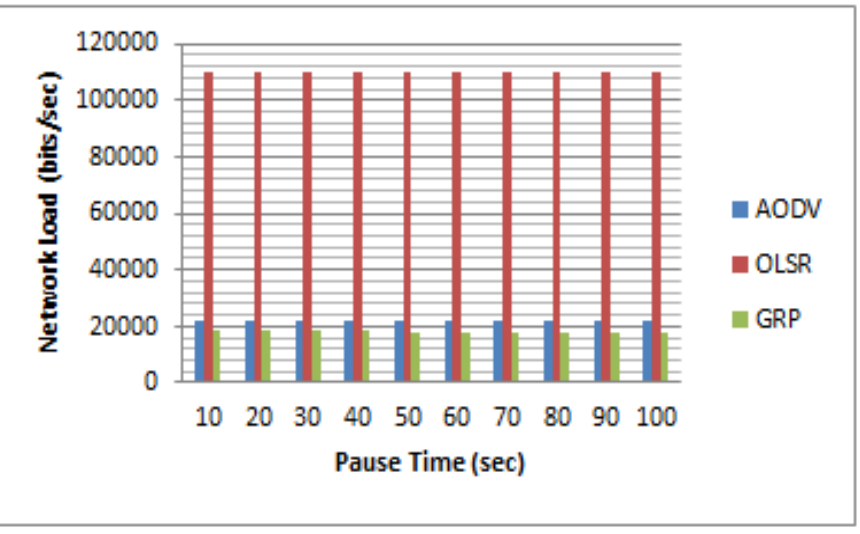

d. HWM (2m/s)

Fig. 4. Network Load. 


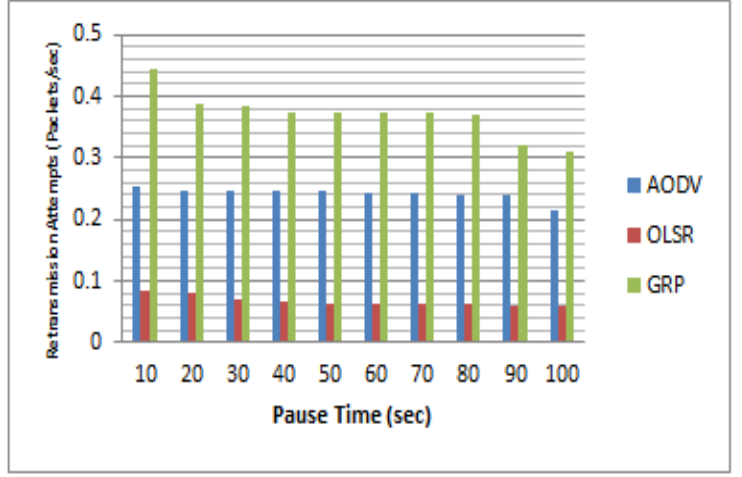

a.FCM $(30 \mathrm{~m} / \mathrm{s})$

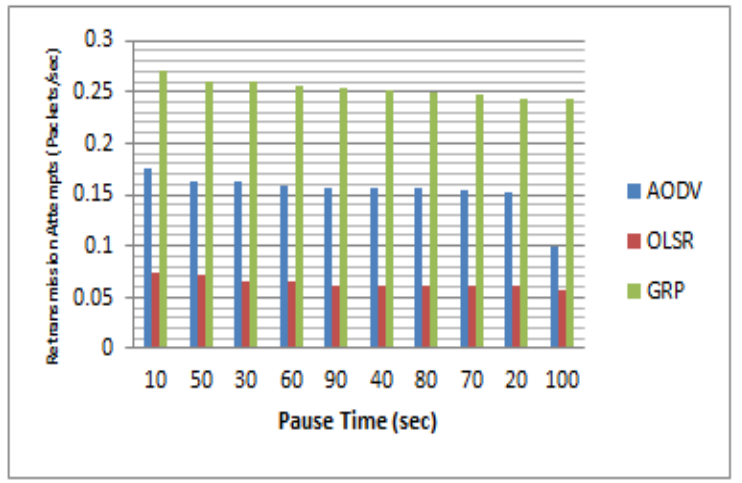

$\operatorname{c.RWM}(4 \mathrm{~m} / \mathrm{s})$

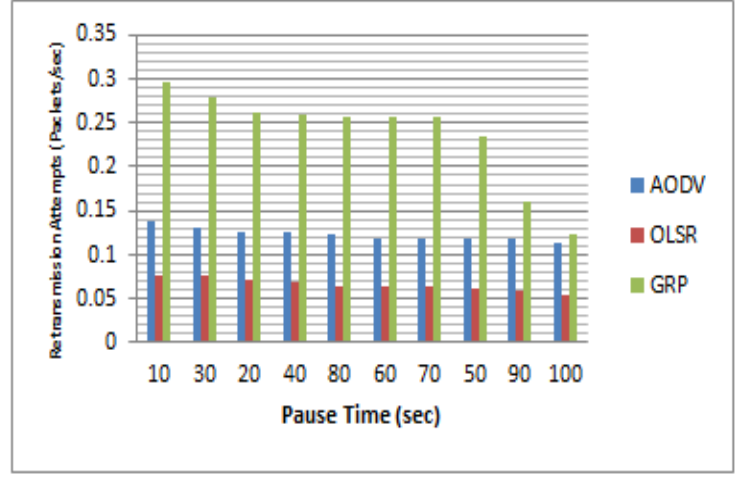

b.SCM $(10 \mathrm{~m} / \mathrm{s})$

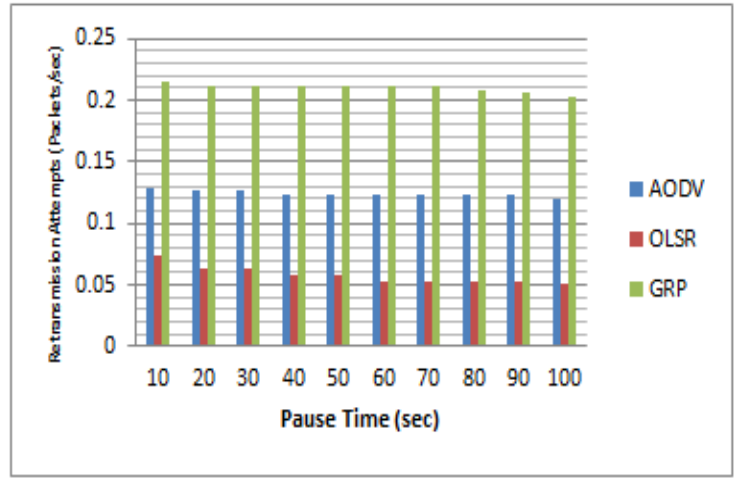

d.HWM $(2 \mathrm{~m} / \mathrm{s})$

Fig. 5. Retransmission Attempts.

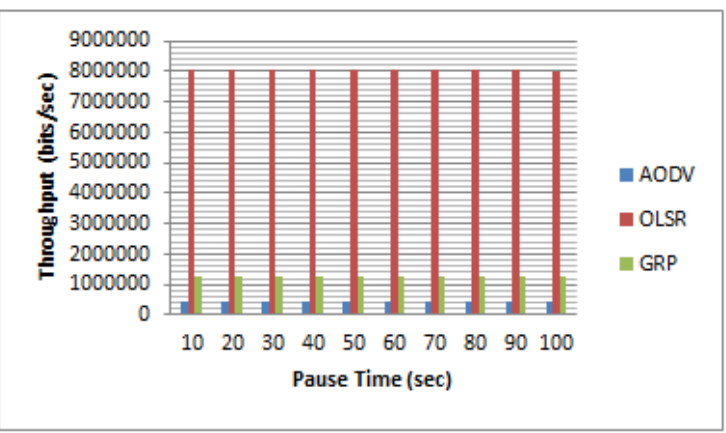

a.FCM $(30 \mathrm{~m} / \mathrm{s})$

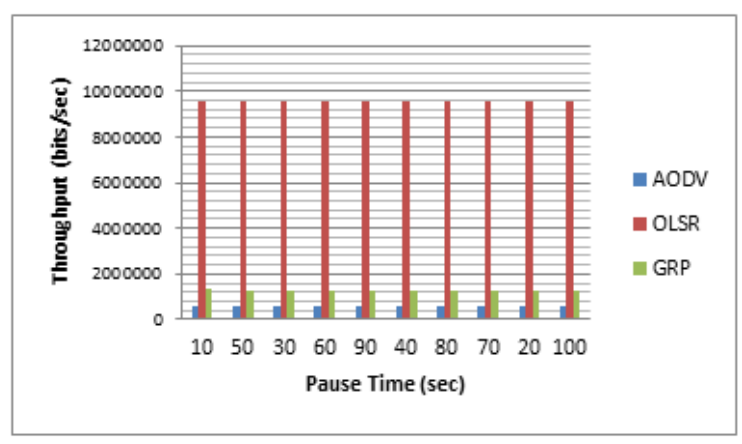

c. $R W M(4 \mathrm{~m} / \mathrm{s})$

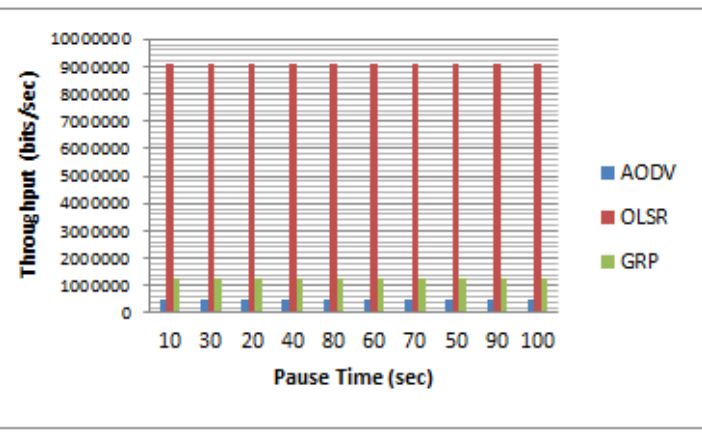

b. $\operatorname{SCM}(10 \mathrm{~m} / \mathrm{s})$

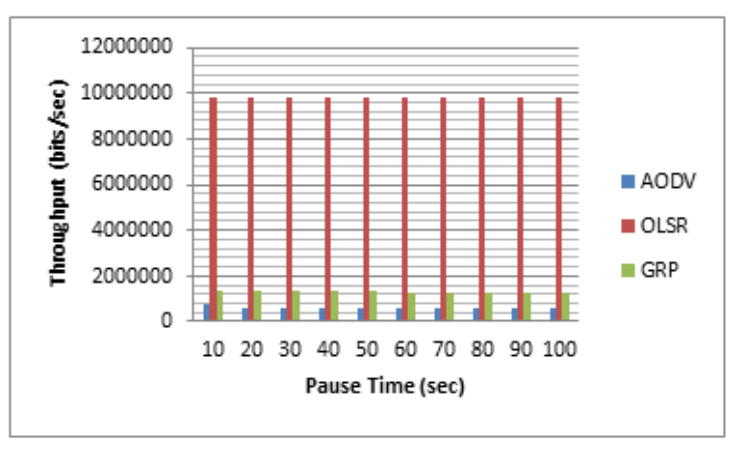

d. HWM ( $2 \mathrm{~m} / \mathrm{s})$

Fig. 6. Throughput. 
TABLE II. AVERAGE RESULTS FOR AODV, OLSR, AND GRP PROTOCOLS

\begin{tabular}{|c|c|c|c|c|c|c|c|c|}
\hline & & Parameters & Data & End -to- & Media & Network & Retransmission & Throughnut \\
\hline & & Protocols & bits/sec & (sec) & (sec) & & & \\
\hline FCM & $30 \mathrm{~m} / \mathrm{s}$ & AODV & 271.6803 & 0.006519 & 0.012776 & 29826.48 & 0.2421 & 430287.3 \\
\hline Pause & ע & OLSR & 1941.048 & 0.000684 & 0.004156 & 120102.4 & 0.0672 & 8034218 \\
\hline (sec) & $(10,20,00,+0,00,00, / 0,00,70,100)$ & GRP & 1454.679 & 0.001478 & 0.003853 & 56132.8 & 0.3715 & 1238861 \\
\hline SCM & $10 \mathrm{~m} / \mathrm{s}$ & AODV & 76.358 & 0.005411 & 0.011469 & 24442.48 & 0.1531 & 505787.3 \\
\hline Pause & & OLSR & 1708.171 & 0.000575 & 0.003826 & 114767.6 & 0.0661 & 9075352 \\
\hline$(\mathrm{sec})$ & (1) & GRP & 1266.727 & 0.001428 & 0.003694 & 52285.55 & 0.2535 & 1279313 \\
\hline RWM & $4 m / s$ & AODV & 71.932 & 0.004531 & 0.00793 & 24106.29 & 0.1244 & 574473.3 \\
\hline Pause & 60 & OLSR & 1590.796 & 0.000452 & 0.00382 & 111749.7 & 0.0642 & 9584649 \\
\hline$(\mathrm{sec})$ & $(10,20,00,+0,00,00, / 0,00,70,100)$ & GRP & 1146.504 & 0.001316 & 0.00367 & 50895.41 & 0.2384 & 1288852 \\
\hline HWM & $2 \mathrm{~m} / \mathrm{s}$ & AODV & 63.63183 & 0.003799 & 0.007179 & 21968.23 & 0.1232 & 611671.4 \\
\hline Pause & & OLSR & 1212.325 & 0.000368 & 0.00364 & 110198.5 & 0.0582 & 9810472 \\
\hline (sec) & & GRP & 1179.5 & 0.001201 & 0.003328 & 17970.58 & 0.2101 & 1312141 \\
\hline
\end{tabular}

\section{CONCLUSION}

In this work, instead of evaluating the performances of routing protocols according to the number of nodes and traffic load, the performance evaluation completed based on the four mobility models namely FCM $(30 \mathrm{~m} / \mathrm{s})$, SCM $(10 \mathrm{~m} / \mathrm{s})$, RWM $(4 \mathrm{~m} / \mathrm{s})$ and HWM $(2 \mathrm{~m} / \mathrm{s})$. AODV, OLSR and GRP are the protocols' where the performances analyzed. Furthermore, for more accurate results we have taken ten different pause time values $(10,20,30,40,50,60,70,80,90$, and $100 \mathrm{sec})$ for the performance evaluations of AODV, OLSR, and GRP protocols. In this experiment we found that the performances of these protocols are varying from one model to another. Therefore the results from one model cannot form a basis for other models. Regarding the end-to-end delay, retransmission attempts, and throughput, OLSR protocol has the ability to provide the best performance. Therefore, OLSR is an appropriate routing protocol for a network that requires a low delay, retransmission attempt, and high throughput for transferring data from the source node to the destination node. It might also be observed from the simulation results that AODV protocol performed better than OLSR and GRP in terms of data drop rate and network load in all models. However, AODV network load was a bit high in the HWM model compared to the GRP protocol. In addition, GRP has lower media access delay and higher throughput than AODV for all cases. Based on the results obtained, it can be said that, the type of application plays an important role on the decision of the routing protocol that should be used in the network. For instance, the OLSR protocol can be used to provide support for real-time applications.

\section{REFERENCES}

[1] Yadav, A. (2016). Cross-Layer Optimization for Protocols In Mobile Adhoc Networks (Doctoral Dissertation, Uttar Pradesh Technical University).

[2] Bandakkanavar, R. (2018). Security Aspects in Mobile Ad Hoc Networks - Krazytech. [online] Krazytech. Available at: https://krazytech.com/technical-papers/security-aspects-in-mobile-adhoc-network-manets [Accessed 24 Feb. 2018].

[3] Abuhmida, M., Radhakrishnan, K., \& Wells, I. (2015, March). Performance Evaluation of Mobile Ad Hoc Routing Protocols on Wireless Sensor Networks for Environmental Monitoring. In Modelling and Simulation (UKSim), 2015 17th UKSim-AMSS International Conference on (pp. 544-548).

[4] Toor, Y., Muhlethaler, P., \& Laouiti, A. (2008). Vehicle ad hoc networks: Applications and related technical issues. IEEE communications surveys \& tutorials, 10(3).

[5] Sichitiu, M. L., \& Kihl, M. (2008). Inter-vehicle communication systems: a survey. IEEE Communications Surveys \& Tutorials, 10(2).

[6] Willke, T. L., Tientrakool, P., \& Maxemchuk, N. F. (2009). A survey of inter-vehicle communication protocols and their applications. IEEE Communications Surveys \& Tutorials, 11(2).

[7] Rangarj, J., \& Anitha, M. (2016). Impact of Different Mobility on AODV and DSDV Routing Protocol for MANET. Middle-East Journal of Scientific Research, 24(12): 3797-3797.

[8] Kumari, N., Gupta, S. K., Choudhary, R., \& Agrwal, S. L. (2016, March). New performance analyzes of AODV, DSDV and OLSR routing protocol for MANET. In Computing for Sustainable Global Development (INDIACom), 2016 3rd International Conference on (pp. 33-35).

[9] Appiah, M., \& Cudjoe, R. (2017, December). The Impact of Routing Protocols on the Performance of a Mobility Model in Mobile Ad Hoc Network (MANET). In International Conference on Security, Privacy and Anonymity in Computation, Communication and Storage (pp. 361368). Springer, Cham. 
[10] Shams, A., Jan, M. \& Irfan, H. (2007). Performance Evaluation of MANET Routing Protocols Using Scenario-Based Mobility Models, Innovative Algorithms and Techniques in Automation, Industrial Electronics and Telecommunications, (419-424). Springer.

[11] Sasidharan, D., \& Jacob, L. (2018). Improving Network Lifetime and Reliability for Machine Type Communications based on LOADng Routing Protocol. Ad Hoc Networks.

[12] Abdullah, A. M., \& Aziz, R. H. H. (2014). The Impact of Reactive Routing Protocols for Transferring Multimedia Data over MANET. Journal of Zankoy Sulaimani-Part A, 16, 4.

[13] Zhang, Y., Liu, W., Lou, W., \& Fang, Y. (2006). MASK: anonymous ondemand routing in mobile ad hoc networks. IEEE transactions on wireless communications, 5(9), 2376-2385.

[14] Abdullah, A. M. (2015). Investigating on Mobile Ad-Hoc Network to Transfer FTP Application. International Journal of Advanced Computer Science and Applications, 6(7), 172-183.

[15] Clausen, T., \& Jacquet, P. (2003). Optimized link state routing protocol (OLSR) (No. RFC 3626).

[16] Kulla, E., Hiyama, M., Ikeda, M., \& Barolli, L. (2012). Performance comparison of OLSR and BATMAN routing protocols by a MANET testbed in stairs environment. Computers \& Mathematics with Applications, 63(2), 339-349.

[17] Mohapatra, S., \& Kanungo, P. (2012). Performance analyzes of AODV, DSR, OLSR and DSDV routing protocols using NS2 Simulator. Procedia Engineering, 30, 69-76.
[18] Bhangwar, N. H., Halepoto, I. A., Sadhayo, I. H., Khokhar, S., \& Laghari, A. A. (2017). On Routing Protocols for High Performance. Studies in Informatics and Control, 26(4), 441-448.

[19] Zhiyuan, L. (2009, October). Geographic routing protocol and simulation. In Computer Science and Engineering, 2009. WCSE'09. Second International Workshop on (Vol. 2, pp. 404-407). IEEE.

[20] Stojmenovic, I., \& Lin, X. (2001). Loop-free hybrid single-path/flooding routing algorithms with guaranteed delivery for wireless networks. IEEE Transactions on Parallel and Distributed Systems, 12(10), 1023-1032.

[21] Bose, P., Morin, P., Stojmenović, I., \& Urrutia, J. (2001). Routing with guaranteed delivery in ad hoc wireless networks. Wireless networks, 7(6), 609-616.

[22] Johnson, D. B., \& Maltz, D. A. (1996). Dynamic source routing in ad hoc wireless networks. In Mobile computing (pp. 153-181). Springer, Boston, MA.

[23] Bai, F., \& Helmy, A. (2004). A survey of mobility models. Wireless Adhoc Networks. University of Southern California, USA, 206, 147.

[24] Dardan, M, Arianit, M. (2015). Performance Analysis of WLAN $802.11 \mathrm{~g} / \mathrm{n}$ Standards using OPNET (Riverbed) Application 57th International Symposium ELMAR, Zadar, Croatia, 22(9), pp.30-35.

[25] Natarajan, K., \& Mahadevan, G. (2017). Mobility based performance analysis of MANET routing protocols. International Journal of Computer Applications, 163(10), 37-43. 